\title{
A young adult with nephrotic syndrome following COVID-19 vaccination
}

\author{
Kei Nagai $^{1,2}$ (1) Mikiko Kageyama $^{1} \cdot$ Mamiko Iwase $^{1} \cdot$ Atsushi Ueda $^{1}$
}

Received: 25 November 2021 / Accepted: 2 December 2021 / Published online: 4 January 2022

(c) Japanese Society of Nephrology 2021

\section{To the Editor}

We read with great interest the recent report of newly developed nephrotic syndrome (NS) following coronavirus disease 2019 (COVID-19) vaccination in a child [1]. As noted in their review, several cases of NS have been reported in middle-aged and highly aged adults ranging in age from 41 years to the 80s after COVID-19 [1]. New-onset NS has not been reported in young adults (15-35 years old), whereas the indications for COVID-19 vaccines have been expanded to include young ages.

A case of newly developed NS following the first dose of COVID-19 vaccination (BNT162b2 [Pfizer-BioNTech]) is presented (Fig. 1). A 22-year-old man with no previous history and no occupational risk of renal diseases visited the emergency department of our hospital. Sixteen days earlier, he was given the first COVID-19 vaccination based on the government's policy. The swelling of the injection site on his upper arm and local muscle pain had lasted for 1 week. Subsequently, he became aware of facial and leg edema (day -9). At the first emergency department visit (day 0 ), the laboratory data showed massive proteinuria $(14.4 \mathrm{~g} /$ day $)$ and hypoalbuminemia $(1.4 \mathrm{~g} / \mathrm{dL})$ without any hematuria. The selectivity index was 0.11 , and there were few notable findings on serological studies, which showed normal C-reactive protein $(0.08 \mathrm{mg} / \mathrm{dL})$, immunoglobulin (IgG $299 \mathrm{mg} / \mathrm{dL}, \operatorname{IgA} 179 \mathrm{mg} / \mathrm{dL}$, and IgM $72 \mathrm{mg} / \mathrm{dL}$ ), and complement (C3 $148 \mathrm{mg} / \mathrm{dL}, \mathrm{C} 444 \mathrm{mg} / \mathrm{dL}$, and CH50 59 $\mathrm{U} / \mathrm{mL}$ ) levels and negative results for anti-nuclear antibody. On the basis of these findings, NS was diagnosed, with clinical suspicion that it was minimal change NS (MCNS). He

Kei Nagai

knagai@md.tsukuba.ac.jp

1 Department of Nephrology, Hitachi General Hospital, 2-1-1 Jonan-cho, Hitachi, Ibaraki 317-0077, Japan

2 Department of Nephrology, Faculty of Medicine, University of Tsukuba, 1-1-1 Ten-nodai, Tsukuba, Ibaraki 305-8575, Japan was immediately hospitalized and given intravenous heparin because of a coagulation abnormality (fibrinogen $812 \mathrm{mg} /$ dL). After hospitalization, he was treated with an oral prednisolone $1 \mathrm{mg} / \mathrm{kg} /$ day and furosemide $40 \mathrm{mg}$ intravenously. Fortunately, he did not have renal dysfunction, and improvement of edema appeared on the second day of admission. The clinical signs of NS improved steadily, and urinary protein had completely disappeared on the seventh day. On the 17th day, he was transferred to another hospital, because he wanted treatment at a medical institution near his residence.

Establishing herd immunity against COVID-19 is a pressing need for controlling the pandemic. Therefore, we recognize that a realistic path to population immunity is vaccination of a wide range of age groups. Exactly how the immune response induced by the vaccine will improve the pathophysiology of COVID-19 remains unknown [2]. COVID-19 vaccination induces various immunological reactions, particularly a Th1-dominant response [3], which may induce glomerular disease including nephrotic syndrome [4]. However, there is no direct evidence for causality linking COVID-19 vaccination and MCNS in the present case and others [1].

Nevertheless, we should be careful not to overlook newly developed proteinuria and edema, as well as common side effects due to vaccination, in young adults to elderly persons. Moreover, whether the second dose of vaccination should be given in such cases remains a question.

Acknowledgements The authors would like to thank Satoshi Hara and Takumi Kurita for their clinical support. 
Fig. 1 Clinical course. Sixteen days before admission, the patient receives the first dose of the COVID-19 vaccine. He develops local muscle pain without systemic symptoms for 1 week, but it is self-limited. Subsequently, facial edema, leg edema, and weight gain occur. On visiting our hospital, he is diagnosed with newly developed nephrotic syndrome (NS) and treated with prednisolone, heparin, and diuretics. Clinical signs of NS improve steadily, and urinary protein disappears completely on the seventh day

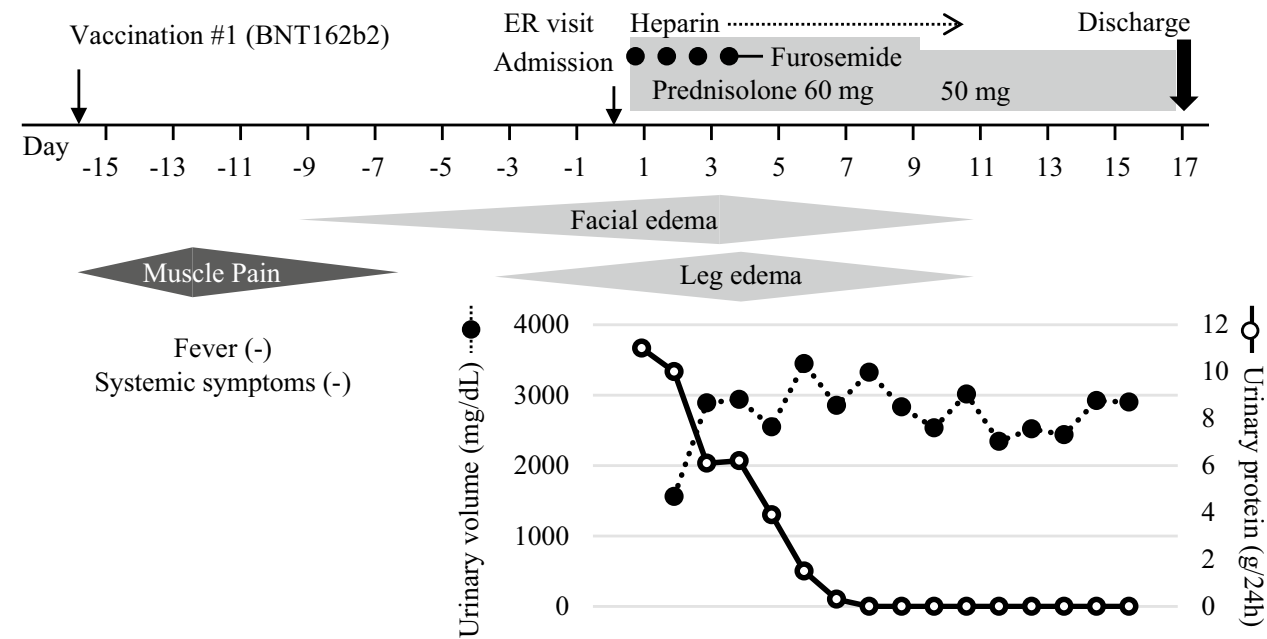

Body Weight ( $\mathrm{kg}) \quad 55.0$ (baseline)

Total protein $(\mathrm{g} / \mathrm{dL})$

Serum albumin $(g / d L)$

Hematuria (Dipstick)
$\begin{array}{llllll}64.9 & 63.0 & 58.7 & 55.4 & 52.4 & 51.6\end{array}$
$\begin{array}{llllll}3.8 & 4.2 & 3.5 & 3.9 & 4.3 & 5.2\end{array}$
$\begin{array}{llllll}1.4 & 1.4 & 1.2 & 1.5 & 1.9 & 2.9\end{array}$
$(-) \quad(-) \quad(-) \quad(-)$
$(-)$

\section{Declarations}

Conflict of interest All the authors have declared no competing interest.

Informed consent Informed consent for publication was obtained from the patient described in this report.

\section{References}

1. Nakazawa E, Uchimura T, Hirai $\mathrm{Y}$, et al. New-onset pediatric nephrotic syndrome following Pfizer-BioNTech SARS-CoV-2 vaccination: a case report and literature review [published online ahead of print, 2021 Nov 15]. CEN Case Rep. 2021;1-5.
2. Miyasaka M. COVID-19 and immunity: quo vadis? Int Immunol. 2021;33(10):507-13.

3. Sahin U, Muik A, Vogler I, et al. BNT162b2 vaccine induces neutralizing antibodies and poly-specific T cells in humans. Nature. 2021;595(7868):572-7.

4. Abeyagunawardena AS, Goldblatt D, Andrews N, Trompeter RS. Risk of relapse after meningococcal $\mathrm{C}$ conjugate vaccine in nephrotic syndrome. Lancet. 2003;362:449-50.

Publisher's Note Springer Nature remains neutral with regard to jurisdictional claims in published maps and institutional affiliations. 